\title{
Inibidor de Tripsina em Raízes de Eucalyptus urophylla*
}

\author{
Célia R. Tremacoldi ** \& Sérgio F. Pascholati \\ Departamento de Entomologia, Fitopatologia e Zoologia Agrícola, ESALQ/USP, Cx. Postal 9, CEP 13418-900, \\ Piracicaba, SP, Fax (019) 3434-4839, e-mail: sfpascho@esalq.usp.br
}

(Aceito para publicação em 14/11/2003)

Autor para correspondência: Sérgio Florentino Pascholati

TREMACOLDI, C.R. \& PASCHOLATI, S.F. Inibidor de tripsina em raízes de Eucalyptus urophylla. Fitopatologia Brasileira 29:135-140. 2004.

\section{RESUMO}

As raízes de eucalipto (Eucalyptus urophylla) podem estar associadas a fungos como Pisolithus tinctorius, formando uma simbiose conhecida como ectomicorriza, mas também podem estar colonizadas por fungos patogênicos, como Rhizoctonia solani, agente causal do tombamento de plantas em viveiros. O objetivo deste trabalho foi verificar a presença de atividade inibitória de tripsina, uma serino-protease, em raízes de E. urophylla e a atividade de tripsina em filtrados desses fungos. Alíquotas de extrato protéico bruto de raízes de E. urophylla e frações protéicas parcialmente purificadas por cromatografia de exclusão molecular, do tipo Sephacryl S-100HR, foram testadas para atividade inibitória de tripsina. Proteínas do extrato ou das frações, quando incubadas com o substrato BAPNA
(? -benzoil-arginina- $p$-nitroanilida) e tripsina comercial na presença de tampão Tris- $\mathrm{HCl} 0,1 \mathrm{M}(\mathrm{pH} 8,0)$, resultou em atividade de inibidor de tripsina ao redor de $80 \%$. Filtrados de meios de cultura de $P$. tinctorius e $R$. solani foram parcialmente purificados em cromatografia de exclusão molecular, porém atividade de tripsina sobre o substrato BAPNA não foi verificada em nenhuma das frações. Portanto, não foi possível estabelecer uma correlação direta entre o inibidor da planta e proteases dos fungos. Os resultados apresentados abrem novas perspectivas para o estudo dessas proteínas nas interações entre patógenos e simbiontes para espécies de eucalipto.

Palavras-chave adicionais: inibidor de protease, protease, ectomicorriza, Rhizoctonia solani.

\section{ABSTRACT}

\section{Trypsin inhibitor from roots of Eucalyptus urophylla}

Roots of eucalyptus (Eucalyptus urophylla) can be associated with fungi such as Pisolithus tinctorius, thus forming an ectomycorrhiza, or be colonized by pathogenic fungi, such as Rhizoctonia solani, agent of damping-off in nursery plants. The objective of this work was to verify the presence and activity of trypsin inhibitor, a serino-protease, in roots of E. urophylla and the activity of trypsin in filtrate of these fungi. The crude protein extract from roots and fractions partially purified by molecular sieving chromatography, using Sephacryl S-100-HR, was tested for trypsin inhibitory activity. The protein extracts or fractions, when incubated with BAPNA (? -benzoyl-arginyl- $p$-nitroanilide) as substrate, in presence of $0.1 \mathrm{M}$ Tris-HCl buffer ( $\mathrm{pH} 8,0$ ), showed activity of trypsin inhibitor around $80 \%$. Culture filtrates from $P$. tinctorius and $R$. solani isolates were also semi-purified by chromatography; however, no trypsin activity on BAPNA substrate was observed. Due to this, it was impossible to establish a direct correlation between the plant inhibitor and potential fungal proteases. The results presented here open new perspectives for the study of proteins in the interactions between pathogens and symbionts with eucalyptus species.

\section{INTRODUÇÃO}

Plantas e seus patógenos co-participam de inúmeros processos bioquímicos, onde as primeiras tentam defender-se e os segundos colonizar os tecidos de seus hospedeiros. $\mathrm{O}$ resultado final destes processos determina se ocorrerá infecção bem sucedida pelo patógeno, causando doença, ou não. As enzimas de patógenos que atacam paredes celulares vegetais, como proteases, celulases e pectinases, interagindo com proteínas sintetizadas pelas plantas e que podem inibi-las, são um exemplo desses sistemas bioquímicos.

Os inibidores de proteases constituem-se em mais um elemento dentre os vários mecanismos vegetais de defesa contra microrganismos fitopatogênicos. Embora a grande maioria das pesquisas já publicadas para esses inibidores

\footnotetext{
*Parte da Tese de Doutorado do primeiro autor. ESALQ/USP. (2001) **Bolsista da CAPES.
}

concentre-se na defesa de plantas contra insetos herbívoros, há um interesse recente da Fitopatologia no assunto. O papel dos inibidores de proteases nas interações planta-microrganismo ainda não é claro, mas considera-se que atuem na defesa das plantas principalmente por retardar a proteólise de paredes celulares e de proteínas da membrana, reduzindo a desorganização celular e dificultando a atuação de patógenos (Sikes \& Maxcy, 1979; Richardson, 1991).

Plantas, microrganismos e animais contêm proteínas que apresentam a propriedade de formar complexos proteínaproteína, reversíveis ou não, com várias enzimas proteolíticas, promovendo a inibição da atividade dessas proteases por competição pelo seu sítio catalítico. Estas proteínas recebem o nome de inibidores de proteases e são moléculas cuja massa molecular varia de 10 a $90 \mathrm{kDa}$, na maioria dos casos (Richardson, 1991). São denominados de acordo com a protease inibida e/ou sua fonte como, por exemplo, o inibidor de tripsina de soja [Glycine max (L.) Merril] (Kunitz, 1947). 
Os inibidores de proteases mais conhecidos e estudados são aqueles que afetam a atividade de serino-proteases, cisteínoproteases, proteases aspárticas e metaloproteases, que são os quatro grandes grupos aos quais pertencem as enzimas proteolíticas (Laskowski \& Kato, 1980). Os inibidores de tripsina, uma serino-protease, concentram o maior número de pesquisas no assunto, sendo as famílias Solanaceae, Leguminosae e Gramineae as mais investigadas quanto à atividade de inibidores, por representarem importantes fontes de alimentos (Richardson, 1991).

A especificidade da inibição é altamente variável. Alguns inibidores de proteases são capazes de inibir apenas uma ou duas proteases, estritamente relacionadas, enquanto outros são ativos contra diferentes enzimas dentro de uma mesma classe (Weder, 1986). A maioria dos inibidores de proteases é resistente à desnaturação pelo calor, extremos de pH e à ação de algumas enzimas proteolíticas (Hartl et al., 1986). Poucos estudos foram feitos quanto à sua localização celular, mas sabe-se que são encontrados em paredes celulares, espaços intercelulares, no citossol e em vacúolos (Kapur et al., 1989).

As proteases extracelulares de fungos e bactérias patogênicos a plantas podem participar dos processos de penetração e infecção (Sikes \& Maxcy, 1979). Muitos inibidores são ativos in vitro contra proteases produzidas por microrganismos (Yoshikawa et al., 1976; Mosolov et al., 1979; Brown \& Adikaram, 1983; Mosolov \& Shulgin, 1986; Pekkarinen \& Jones, 2003) e diferenças no acúmulo de inibidores entre interações compatíveis e incompatíveis associam estas proteínas aos conceitos de suscetibilidade ou resistência, respectivamente (Peng \& Black, 1976; Giri et al., 1998).

Raízes de espécies de eucalipto (Eucalyptus spp.) podem associar-se a fungos endomicorrízicos, principalmente em plantios jovens, e a ectomicorrízicos já em plantios adultos (Peterson \& Farquhar, 1994). Por exemplo, o fungo Pisolithus tinctorius (Pers.) Coker \& Couch é comum em solos florestais em associação ectomicorrízica com eucalipto (Marx, 1977; Malajczuk et al., 1990). Por outro lado, importantes patógenos também causam doenças nesta planta via raízes, como o fungo Rhizoctonia solani Kühn, responsável pelo tombamento de mudas e podridão de estacas (Krugner \& Auer, 1997).

Em plantas arbóreas, como o eucalipto, há um único relato, até o momento, sobre a presença de inibidores de proteases. Sementes de Eucalyptus urophylla S. T. Blake apresentaram um inibidor de tripsina, capaz de inibir em até $80 \%$ a atividade de tripsina comercial e de inibir, também, o crescimento in vitro de isolados de $P$. tinctorius (Tremacoldi $\&$ Pascholati, 2002). Neste contexto, o objetivo deste trabalho foi verificar a presença de inibidores de proteases em raízes de E. urophylla, tendo em vista possíveis correlações entre os inibidores encontrados e proteases liberadas por $R$. solan $i$ e $P$. tinctorius, como uma ferramenta na tentativa de se elucidar os mecanismos bioquímicos e fisiólogicos que regem interações entre plantas e microrganismos e que diferenciam aquelas patogênicas das simbióticas.

\section{MATERIAL E MÉTODOS}

\section{Obtenção das raízes a partir de plântulas}

Sementes de E. urophylla (Instituto de Pesquisas Florestais da ESALQ/USP - lote AN - 458, talhão T8170, Anhembi/SP) foram utilizadas para a obtenção de raízes, a partir de plântulas.

Na tentativa de se estabelecer um sistema de cultivo que permitisse um crescimento satisfatório das plântulas e com raízes isentas de resíduos, alguns testes preliminares foram realizados. Assim, solução de Sarruge concentrada (Sarruge, 1974) foi primeiramente diluída dez vezes em água destilada e, depois, na proporção 1:1 (v/v). Esta solução final foi adicionada de $0,25 \%, 0,5 \%$ ou $2 \%(\mathrm{~m} / \mathrm{v})$ de ágar, sendo $8 \mathrm{ml}$ transferidos para cada tubo de vidro com $19 \mathrm{~mm}$ de diâmetro por $97 \mathrm{~mm}$ de altura. Os tubos com o meio de cultivo foram autoclavados, com cinco repetições para cada quantidade de ágar testada. Para cada tubo de ensaio foi transplantada uma plântula, recém-germinada em placas contendo ágar-água, com um par de folhas cotiledonares e, aproximadamente, $1 \mathrm{~cm}$ de altura. A vedação foi realizada com algodão e a porção inferior de cada tubo foi envolta por papel alumínio até a altura do meio de cultivo, de tal maneira que as raízes a serem formadas ficassem no escuro. A incubação foi feita em câmara de crescimento a $28^{\circ} \mathrm{C}$ ? 2 , sob fotoperíodo $12 / 12 \mathrm{~h}$, ou seja, $12 \mathrm{~h}$ de escuro seguidas por $12 \mathrm{~h}$ de luz fluorescente, durante 45 dias.

A avaliação das plântulas assim produzidas permitiu a escolha da melhor combinação Sarruge:ágar, a qual foi utilizada para a produção das plântulas que serviram para a obtenção das raízes necessárias para a extração do extrato protéico.

\section{Obtenção do extrato protéico de raízes}

As raízes de cada plântula foram retiradas dos tubos, lavadas em água destilada e secas ao ar até peso constante, por aproximadamente três dias. De 560 plântulas, um total de $320 \mathrm{mg}$ de raízes secas foi utilizado para a extração de proteínas.

As raízes foram congeladas em nitrogênio líquido e maceradas até se obter um pó fino. Ao pó foram adicionados $30 \mathrm{ml}$ de solução salina $(\mathrm{NaCl} 15 \%, \mathrm{~m} / \mathrm{v})$, ficando a suspensão sob agitação por $30 \mathrm{~min}$ e sendo posteriormente centrifugada a $12.300 \mathrm{~g}$ por $25 \mathrm{~min}$, a $4{ }^{\circ} \mathrm{C}$. O sobrenadante foi recolhido e precipitado com um volume 4 vezes maior de acetona, mantida em banho de gelo, sendo o material centrifugado novamente, como mencionado acima. As proteínas precipitadas foram ressuspensas em $10 \mathrm{ml}$ de tampão Tris-HCl 0,1 M (pH 8,0) e a suspensão ficou sob agitação por $15 \mathrm{~min}$. Após a centrifugação, o sobrenadante foi recolhido e mantido em congelador (-20 ${ }^{\circ} \mathrm{C}$ ) até sua utilização para os testes de atividade inibitória.

\section{Ensaio para atividade inibitória de tripsina no extrato protéico bruto de raízes de $E$. urophylla}

O extrato protéico bruto de raízes de E. urophylla foi quantificado quanto à concentração de proteínas totais e testado para a atividade inibitória de tripsina. Para a obtenção 
da curva de inibição, volumes de 30, 50, 75, 90, 100, 125, 175 e 200 ? 1 do extrato bruto foram incubados com 1 ? g de tripsina de pâncreas bovino (Sigma), diluída em $\mathrm{HCl} 1 \mathrm{mM}$, e com volume variável de tampão Tris- $\mathrm{HCl} 0,1 \mathrm{M}(\mathrm{pH} 8,0)$, contendo $\mathrm{CaCl}_{2} 0,01 \mathrm{M}$, até se atingir um volume final de 600 ?1 por tubo. A mistura foi incubada por $10 \mathrm{~min}$ a $37^{\circ} \mathrm{C}$ e a seguir foram adicionados 500 ? 1 do substrato BAPNA (benzoilarginina-p-nitroanilida $1 \mathrm{mM}$ em dimetil-sulfóxido de sódio) a cada tubo e procedeu-se a mais 40 min de incubação a 37 ${ }^{\circ} \mathrm{C}$. A reação foi finalizada pela adição de 500 ?1 de ácido acético $30 \%(\mathrm{v} / \mathrm{v})$. As reações foram realizadas em duplicata, tanto para cada dose testada do extrato protéico quanto para os respectivos controles, os quais constavam da adição de ácido acético antes do substrato. O controle representando 100\% da atividade enzimática foi obtido pela mistura de reação sem a presença do extrato de proteínas (Lin et al., 1991). Os resultados foram expressos em atividade residual de tripsina, determinada pela absorbância a $405 \mathrm{~nm}$ contra os controles apropriados para cada reação. $\mathrm{O}$ extrato de raízes também foi aquecido a $70^{\circ} \mathrm{C}$ por $20 \mathrm{~min}$, antes da reação com o substrato, e a atividade obtida foi comparada àquela observada sem o aquecimento prévio.

\section{Purificação do extrato protéico de raízes}

Cromatografia líquida de exclusão molecular foi realizada para o fracionamento das proteínas totais do extrato de raízes de E. urophylla. A coluna utilizada, dimensões de $60 \times 1,5 \mathrm{~cm}$, foi preenchida com o gel Sephacryl S-100-HR (Sigma), equilibrada e eluída com tampão Tris- $\mathrm{HCl} 0,1 \mathrm{M}$, pH 8,0 (Pascholati et al., 1993). As amostras do extrato aplicadas à coluna foram de $1,5 \mathrm{ml}$, eluídas em fluxo de 18 $\mathrm{ml} / \mathrm{h}$, sendo cada fração coletada a cada $3,33 \mathrm{~min}$. O volume de exclusão (Vo) da coluna foi determinado pela passagem de $1 \mathrm{ml}$ de amostra de dextrana azul $(1 \mathrm{mg} / \mathrm{ml})$, nas mesmas condições de fluxo e tempo.

\section{Ensaio para atividade inibitória de tripsina nas frações}

As frações obtidas através da cromatografia foram testadas para verificação da atividade de inibidor de tripsina. Todas as frações tiveram a absorbância determinada a 280 nm em espectrofotômetro e uma alíquota de 50 ?1 de cada uma foi usada em ensaio de atividade inibitória. A estas alíquotas foram adicionados 300 ? 1 de tampão Tris- $\mathrm{HCl}$ 0,1 $\mathrm{M}(\mathrm{pH} 8,0)$ e 10 ? g de tripsina (diluída em $\mathrm{HCl} 1 \mathrm{mM}$ ). Esta reação foi incubada a $37^{\circ} \mathrm{C}$ por $10 \mathrm{~min}$ e a seguir cada tubo recebeu 500 ?1 de BAPNA e foram incubados à mesma temperatura por mais $40 \mathrm{~min}$. A reação foi interrompida pela adição de 500 ? 1 de ácido acético $30 \%$ (v/v). Para cada fração e controles, representando $100 \%$ da atividade enzimática, as reações foram conduzidas em duplicata. Todos os tubos tiveram a absorbância determinada a $405 \mathrm{~nm}$.

\section{Obtenção do filtrado de meio de cultivo de $P$. tinctorius e de $R$. solani}

O isolado 1604 de P. tinctorius foi isolado a partir de ectomicorrizas de Eucalyptus grandis W. Hill ex Maiden (Rio
Claro - SP, pertencente à Micoteca do Departamento de Entomologia, Fitopatologia e Zoologia Agrícola - ESALQ/USP), e $R$. solani isolada de estacas de Eucalyptus sp., com sintomas de apodrecimento. Cada frasco erlenmeyer de $250 \mathrm{ml}$, contendo $50 \mathrm{ml}$ de meio BD (batata-dextrose), foi inoculado com dois discos ( $7 \mathrm{~mm}$ de diâmetro) contendo micélio de cada isolado, crescidos em placas com meio BDA (batata-dextroseágar). As placas com $P$. tinctorius haviam sido incubadas durante 30 dias e as de $R$. solani durante dez dias a $28^{\circ} \mathrm{C}$, no escuro, com cinco repetições para cada fungo. Após o período de incubação dos erlenmeyers, que foi de 30 dias para $P$. tinctorius e de 12 dias para $R$. solani, $5 \mathrm{ml}$ de meio de cultura de cada repetição foram retirados, misturados entre si, passados em papel de filtro comum (Whatman número 40) e novamente filtrados em Millipore 0,2 ?m (Rickauer et al., 1989). Os filtrados de cultura de cada fungo foram quantificados quanto às proteínas totais.

Purificação parcial dos filtrados fúngicos por cromatografia líquida de exclusão molecular e teste para a atividade de tripsina

Os filtrados fúngicos foram submetidos à cromatografia líquida, em coluna empacotada, equilibrada e eluída nas mesmas condições descritas para as amostras de raízes, com a passagem de $1,5 \mathrm{ml}$ de amostra para cada isolado. Todas as frações obtidas tiveram a absorbância determinada a $280 \mathrm{~nm}$ e uma alíquota de 300 ?1 de cada uma foi testada para a atividade de tripsina.

Cada alíquota foi incubada com 200 ? 1 de tampão Tris$\mathrm{HCl} 0,1 \mathrm{M}(\mathrm{pH} 8,0)$, contendo $\mathrm{CaCl}_{2}$ 0,01 M, e 500 ?1 de BAPNA $1 \mathrm{mM}$ em dimetil-sulfóxido de sódio, por $40 \mathrm{~min}$ a $37^{\circ} \mathrm{C}$. Após a incubação, a reação foi interrompida pela adição de 500 ? 1 de ácido acético 30\% (v/v). Cada tubo de reação foi feito em duplicata e apresentou um controle, com a adição do ácido antes do substrato enzimático. A absorbância foi determinada a $405 \mathrm{~nm}$.

\section{Cálculo da concentração de proteínas}

A dosagem de proteínas totais do extrato protéico bruto de raízes e suas frações, bem como dos filtrados fúngicos e respectivas frações, foi feita segundo Bradford (1976), tendo albumina de soro bovino como padrão. A quantificação do extrato bruto de raízes e dos filtrados de cultura possibilitou conhecer o total de proteínas presentes nas amostras submetidas às cromatografias. As dosagens das frações protéicas mostraram quanto do total de proteínas dos extratos apresentava atividade inibitória de tripsina, como um acompanhamento do estágio de purificação das amostras.

\section{RESULTADOS}

Detecção de atividade inibitória de tripsina no extrato protéico bruto de raízes de $E$. urophylla

Um sistema de cultivo que permitiu o crescimento satisfatório das plântulas e com raízes isentas de resíduos foi determinado. O cultivo em vermiculita ou substratos orgânicos, 
utilizados rotineiramente em escala comercial, apresenta a desvantagem da incorporação de resíduos às raízes jovens e porosas, o que é indesejável para fins de análises bioquímicas. As raízes, a partir das quais se obteve o extrato protéico, foram isoladas de plântulas com 45 dias, crescidas em meio de cultivo constituído de solução de Sarruge:água (1:1, v/v) e 0,25\% (m/ v) de ágar, sob fotoperíodo $12 / 12 \mathrm{~h}$, ou seja, $12 \mathrm{~h}$ de escuro seguidas por $12 \mathrm{~h}$ de luz fluorescente, a $28^{\circ} \mathrm{C}$.

A atividade inibitória de tripsina ao redor de $80 \%$ foi detectada em extrato protéico bruto de raízes de $E$. urophylla, usando substrato BAPNA e tripsina de pâncreas bovino (Figura 1). Para se eliminar um possível efeito de lectinas, que poderiam mascarar a atividade do inibidor de tripsina, o extrato de raízes foi aquecido a $70{ }^{\circ} \mathrm{C}$ por $20 \mathrm{~min}$, antes da reação com o substrato. Os inibidores de proteases são resistentes a temperaturas de até $90{ }^{\circ} \mathrm{C}$, mas as lectinas, que são proteínas que se ligam a carboidratos e que são comumente encontradas em tecidos de plantas, não suportam o aquecimento a $70{ }^{\circ} \mathrm{C}$ (Richardson, 1991). Porém, não houve variação da atividade inibitória do extrato com ou sem aquecimento prévio.

\section{Atividade inibitória de tripsina em frações protéicas de raízes de $E$. urophylla, obtidas por cromatografia}

A determinação da absorbância a $280 \mathrm{~nm}$ e da atividade para inibidor de tripsina para todas as frações obtidas através de cromatografia de exclusão molecular revelaram que apenas o primeiro pico continha frações com atividade, a qual também chegou a até $80 \%$ de inibição (Figura 2), como no caso do extrato bruto. $\mathrm{O}$ extrato protéico bruto de raízes continha 18 ?g de proteínas totais por $\mathrm{ml}$. Assim, cada amostra de 1,5 ml, submetida à cromatografia, apresentava 27 ?g de proteínas. As frações com atividade inibitória somaram, aproximadamente, 2 ?g de proteínas, o que correspondeu a $7,4 \%$ do total da amostra.

\section{Atividade de tripsina em filtrados de meio de cultivo dos isolados de $P$. tinctorius e de $R$. solani}

Frações provenientes da cromatografia dos filtrados de culturas de $P$. tinctorius e de $R$. solani, não apresentaram atividade de tripsina sobre o substrato BAPNA nas condições testadas (dados não mostrados).

\section{DISCUSSÃO}

Neste trabalho, foi constatada a existência de inibidor de protease em raízes de E. urophylla, após o primeiro relato da atividade inibitória de tripsina em sementes da mesma planta por Tremacoldi \& Pascholati (2002). A presença de um inibidor de tripsina, com alta capacidade inibitória, foi detectada a partir de extrato protéico de raízes de $E$. urophylla e de frações semipurificadas por cromatografia líquida. É interessante notar que as frações com atividade inibitória mantiveram o mesmo nível de inibição sobre a tripsina comercial que aquele verificado para o extrato protéico bruto, ou seja, ao redor de $80 \%$. Evidenciou-se assim recuperação de $100 \%$ do inibidor de

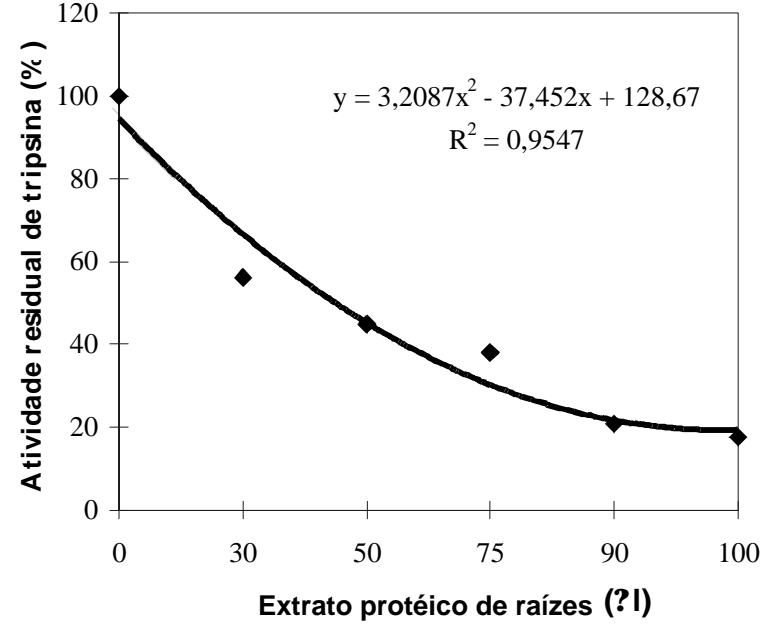

FIG. 1 - Inibição da atividade de tripsina pelo extrato protéico bruto de raízes de Eucalyptus urophylla. Hidrólise de BAPNA $1 \mathrm{mM}$ por tripsina bovina em pH 8,0 a $37{ }^{\circ} \mathrm{C}$, em presença de concentrações crescentes de proteínas totais do extrato.

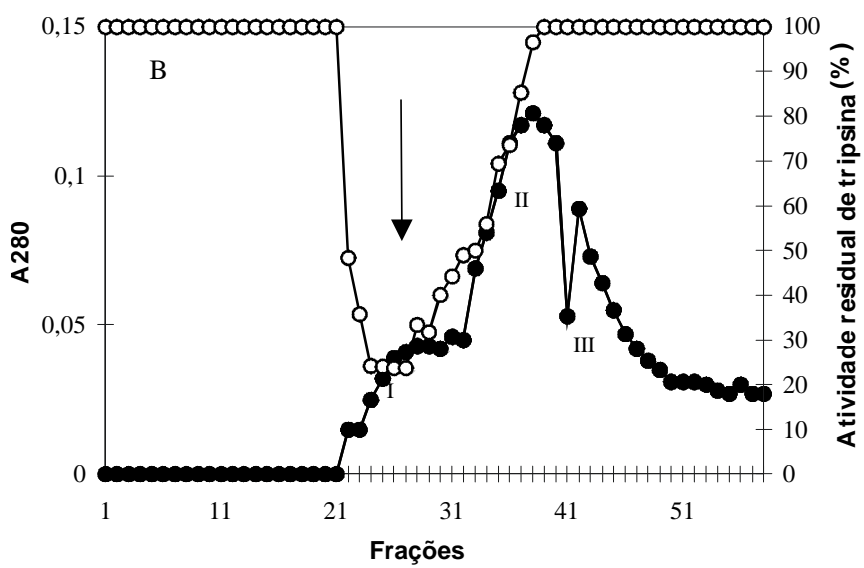

FIG. 2 - Cromatografia de exclusão molecular (Sephacryl S-100HR) do extrato protéico bruto de raízes de Eucalyptus urophylla. A coluna foi equilibrada e eluída com tampão Tris- $\mathrm{HCl} 0,1 \mathrm{M}(\mathrm{pH} 8,0)$. Alíquotas de 50 ?1 de cada fração foram incubadas com o substrato BAPNA 1mM em dimetil-sulfóxido de sódio e com $10 \mathrm{mg}$ de tripsina bovina, em $\mathrm{pH} 8,0$ a $37^{\circ} \mathrm{C}$. A seta corresponde à máxima inibição da atividade enzimática. Absorbância a $280 \mathrm{~nm}(\mathbf{4})$. Atividade residual de tripsina/?1 de fração, em porcentagem (?).

tripsina, não ocorrendo perda de atividade após a cromatografia. Também houve a purificação parcial do inibidor, em relação ao extrato protéico, pois as frações com atividade inibitória representaram apenas $7,4 \%$ do total de proteínas presentes inicialmente na amostra.

O inibidor, provavelmente, atue como parte dos mecanismos de defesa da planta contra insetos e/ou microrganismos patogênicos, além de regular endogenamente a proteólise celular (Kapur et al., 1989; Jongsma \& Bolter, 1997) embora trabalhos envolvendo patógenos e inibidores de proteases de plantas ainda sejam escassos. O primeiro inibidor altamente 
Inibidor de tripsina em raízes de Eucalyptus urophylla

específico para subtilisina, uma protease de Bacillus subtilis Ehrenberg, foi isolado de cevada (Yoshikawa et al., 1976). Outros inibidores de proteases, isolados de plantas, específicos contra proteases de fungos patogênicos já foram descritos para patossistemas como Colletotrichum lindemuthianum (Sacc. \& Magn.) Scribner-feijão (Phaseolus vulagis L.) (Mosolov et al., 1979), Botrytis cinerea (Pers. Ex. Fr)-tomate (Lycopersicon esculentum Mill.) (Brown \& Adikaram, 1986), Fusarium oxysporum f.sp. ciceri Padwick-grão-de-bico (Cicer arietinum L.) (Giri et al., 1998) e Fusarium culmorum (W. G. Smith) Sacc-cevada (Hordeum vulgare L.) (Pekkarinen \& Jones, 2003).

Há um único relato envolvendo inibidores de proteases e fungos simbiontes, como os ectomicorrízicos. Frações do extrato protéico de sementes de E. urophylla, com atividade inibitória de tripsina, obtidas por cromatografia de exclusão molecular, inibiram o crescimento de dois isolados de $P$. tinctorius in vitro, evidenciando a sensibilidade deste fungo ao inibidor de protease da planta hospedeira. O mesmo inibidor, no entanto, não inibiu o crescimento de $R$. solani in vitro (Tremacoldi \& Pascholati, 2002).

Neste trabalho, os resultados obtidos não permitiram estabelecer uma correlação entre o inibidor encontrado nas raízes da planta hospedeira e as proteases dos fungos estudados. $\mathrm{O}$ inibidor apresentou atividade específica sobre tripsina comercial, mas atividade hidrolítica sobre o substrato sintético específico para esta protease não foi detectada nos filtrados de cultura dos fungos. Entretanto, não se pode excluir a possibilidade da presença de proteases necessárias ao metabolismo do simbionte ou do patógeno, que tenham um ou mais resíduos de aminoácidos com afinidade pelo sítio catalítico do inibidor.

Embora os inibidores de proteases, em sua maioria, sejam altamente específicos quanto ao peptídeo a ser clivado, podem também inibir diferentes enzimas dentro de uma mesma classe (Weder, 1986). Dahm \& Strzelczyk (1995) verificaram a atividade proteolítica em alguns isolados de P. tinctorius, mas não utilizaram substratos específicos para a determinação de protease(s) ativa(s). Pekkarinen \& Jones (2002) atribuíram a uma subtilisina e uma tripsina produzidas por F. culmorum o papel de auxiliar a colonização de grãos de cevada e trigo, causando a seca dos ponteiros dessas plantas.

Muitas espécies de vários gêneros de fungos, mesmo que não patogênicos a plantas, apresentam proteases isoladas, caracterizadas e expressas em microrganismos transgênicos, para fins de utilização industrial. As proteases de microrganismos representam ao redor de $60 \%$ de todas as enzimas hidrolíticas comercializadas no mundo, sendo utilizadas principalmente nas indústrias de alimentos, detergentes, farmacêutica e no amaciamento de couros (Gupta et al., 2002). Os principais fungos cujas proteases têm sido isoladas e caracterizadas são Aspergillus spp., Rhizopus spp., Mucor spp. e Penicillium spp. (Rao et al., 1998).

Atualmente, plantas transgênicas resistentes a diversas pragas, através da expressão de inibidores específicos para as enzimas proteolíticas digestivas desses insetos, são comercia- lizadas e cultivadas. Alguns exemplos são as culturas de tabaco (Nicotiana tabacum L.), tomate, algodão (Gossypium hirsutum L.), batata (Solanum tuberosum L.), alfafa (Medicago sativa L.), canola (Brassica napus L.), soja, milho (Zea mays L.) e arroz (Oryza sativa L.) (Jouanin et al., 1998). Conhecendose melhor o papel de inibidores de proteases também nas interações com microrganismos, talvez possam ser obtidas plantas modificadas para a expressão de genes que codifiquem inibidores específicos para proteases de fungos a elas patogênicos.

Estudos decorrentes destes primeiros ensaios sobre inibidores de proteases em uma espécie de eucalipto e de enzimas proteolíticas em microrganismos de interesse para a Fitopatologia, tais como testes de atividade do inibidor encontrado sobre o crescimento fúngico in vitro e in vivo, poderíam estabelecer com maior clareza a atuação de inibidores presentes em raízes de eucalipto em relação aos processos de interação do simbionte e do patógeno.

\section{REFERÊNCIAS BIBLIOGRÁFICAS}

BRADFORD, M.M. A rapid and sensitive method for the quantitation of microgram quantities of protein utilizing the principle of proteindye binding. Annals of Biochemistry 72:248-254. 1976.

BROWN, A.E. \& ADIKARAM, N.K.B. A role for pectinase and protease inhibitors in fungal rot development in tomato fruits. Journal of Phytopathology - Phytopathologische Zeitschrift 106:239-251. 1983.

DAHM, H. \& STRZELCZYK, E. Impact of vitamins on cellulolytic, pectolytic and proteolytic activity of mycorrhizal fungi. Symbiosis 18:233-250. 1995.

GIRI, A.P., HARSULKAR, A.M., PATANKAR, A.G., GUPTA, V.S., SAINANI, M.N., DESHPANDE, V.V. \& RANJEKAR, P.K. Association of induction of protease and chitinase in chickpea roots with resistance to Fusarium oxysporum f. sp. ciceri. Plant Pathology 47:693-699. 1998

GUPTA, R., BEG, Q.K. \& LORENZ, P. Bacterial alkaline proteases: molecular approaches and industrial application. Applied Microbiology and Biotechnology 59:15-32. 2002.

HARTL, P.M., TAN-WILSON, A.L. \& WILSON, K.A. Proteolysis of Kunitz soybean trypsin inhibitor during germination. Phytochemistry 25:23-26. 1986.

JONGSMA, M.A. \& BOLTER, C. The adaptation of insects to plant protease inhibitors. Journal of Insect Physiology 43:885-895. 1997.

JOUANIN, L., BONADÉ-BOTTINO, M., GIRARD, C., MORROT, G. \& GIBAND, M. Transgenic plants for insect resistance. Plant Science 131:1-11. 1998.

KAPUR, R., TAN-WILSON, A.L. \& WILSON, K.A. Isolation and partial characterization of a subtilisin inhibitor from the mung bean (Vigna-radiata). Plant Physiology 91:106-112. 1989.

KRUGNER, T.L. \& AUER, C.G. Doenças do eucalipto. In: Kimati, H., Amorim, L., Bergamim Filho, A., Camargo, L.E.A. \& Rezende, J.A.M. (Eds.). Manual de Fitopatologia: Doenças das Plantas Cultivadas. São Paulo, Editora Agronômica Ceres, 1997. pp.358375 .

KUNITZ, M. Crystalline soybean trypsin inhibitor. II. General 
properties. Journal of Genetic and Physiology 30:291-310. 1947.

LASKOWSKY, M. \& KATO, I. Protein inhibitors of proteinases. Annual Review of Biochemistry 49:593-626. 1980.

LIN, J.Y., CHU, S.C., WU, H.C. \& HSIEH, Y.S. Trypsin inhibitor from the seeds of Acacia confusa. Journal of Biochemistry 110:879883. 1991.

MALAJCZUK, N., LAPEYRIE, F. \& GARBAYE, J. Infectivity of pine and eucalypt isolates of Pisolithus tinctorius on roots of Eucalyptus urophylla in vitro. I. Mycorrhiza formation in model systems. New Phytologist 114:627-631. 1990.

MARX, D.H. Tree host range and world distribution of the ectomycorrhizal fungus Pisolithus tinctorius. Canadian Journal of Microbiology 23:217-233. 1977.

MOSOLOV, V.V. \& SHULGIN, M.N. Protein inhibitors of microbial proteinases from wheat, rye and triticale. Planta 167:595-600. 1986.

MOSOLOV, V.V., LOGINOVA, M.D., MALOVA, E.L. \& BENKEN, I.I. Specific inhibitor of Colletotrichum lindemuthianum protease from Kidney bean (Phaseolus vulgaris) seeds. Planta 144:265-269. 1979.

PASCHOLATI, S.F., DEISING, H., LEITE, B., ANDERSON, D. \& NICHOLSON, R.L. Cutinase and non-especific esterase activities in the conidial mucilage of Colletotrichum graminicola. Physiological and Molecular Plant Pathology 42:37-51. 1993.

PEKKARINEN, A.I. \& JONES, B.L. Purification and identification of barley (Hordeum vulgare L.) proteins that inhibit the alkaline serine proteinases of Fusarium culmorum. Journal of Agricultural and Food Chemistry 51:1710-1717. 2003.

PEKKARINEN, A.I. \& JONES, B.L. Trypsin-like proteinase produced by Fusarium culmorum grown on grain proteins. Journal of Agricultural and Food Chemistry 50:3849-3855. 2002.
PENG, J.H. \& BLACK, L.L. Increased proteinase-inhibitor activity in response to infection of resistant tomato plants by Phytophthora infestans. Phytopathology 66:958-963. 1976.

PETERSON, R.L. \& FARQUHAR, M.L. Mycorrhizas-integrated development between roots and fungi. Mycologia 86:311-326. 1994.

RAO, M.B., TANSKALE, A.M., GHATGE, M.S. \& DESHPANDE, V.V. Molecular and biotechnological aspects of microbial proteases. Microbiology and Molecular Biology Research 62:597-635. 1998.

RICHARDSON, M. Seed storage proteins: the enzyme inhibitors. Methods in Plant Biochemistry 5:259-305. 1991.

RICKAUER, M., FOURNIER, J. \& ESQUERRÉ-TUGAYÉ, M.T. Induction of proteinase inhibitors in tobacco cell suspension culture by elicitors of Phytophthora parasitica var. nicotianae. Plant Physiology 90:1065-1070. 1989.

SARRUGE, J.R. Análises Químicas em Plantas. Anais da Escola Superior de Agricultura "Luiz de Queiroz", Piracicaba 32:191-196. 1974.

SIKES, A. \& MAXCY, R.B. Differentiation of food bacteria on the basis of their ability to utilize different proteins. Journal of Food Science 44:1228-1232. 1979.

TREMACOLDI, C.R. \& PASCHOLATI, S.F. Detection of trypsin inhibitor in seeds of Eucalyptus urophylla and its influence on the in vitro growth of the fungi Pisolithus tinctorius and Rhizoctonia solani. Brazilian Journal of Microbiology 33:281-286. 2002.

WEDER, J.K.P. Nutritional and toxicological significance of enzyme inhibitors in plant foods. Friedman, M. (Ed.). Plenun Press, New York, 1986. pp.299-347.

YOSHIKAWA, M., IWASAKI, T., FUJII, M. \& OOGAKI, M. Isolation and some properties of a subtilisin inhibitor from barley. Journal of Biochemistry 79:765-773. 1976. 